\title{
Marine landscapes and faunal recruitment: a field test with seagrasses and copepods
}

\author{
Susan S. Bell ${ }^{1}$, Geoffrey R. F. Hicks ${ }^{2}$ \\ ${ }^{1}$ Department of Biology, University of South Florida, Tampa, Florida 33620, USA \\ ${ }^{2}$ Department of Crustacea, National Museum of New Zealand, PO Box 467, Wellington, New Zealand
}

\begin{abstract}
The influence of plant landscapes on recruitment of meiofaunal copepods was investigated in a New Zealand seagrass bed. Artificial plant mimics were placed into sediments at levels equivalent to natural blade densities ( 100 units per $0.5 \times 0.25 \mathrm{~m}$ plot) in a variety of experimental treatments and retrieved 3 or $5 \mathrm{~d}$ later. To assess the effect of plant arrangement on faunal recruitment, plots were established within a seagrass bed in areas clipped of vegetation with (1) natural vegetation immediately surrounding the experimental plot; (2) natural vegetation clipped up to $0.5 \mathrm{~m}$ from plot edges; and (3) vegetation clipped up to $1 \mathrm{~m}$ from plot edges. Outside the natural seagrass bed plots were established in unvegetated sediments $0.5 \mathrm{~m}$ from the edge of the bed. Additionally, mimics were placed into plots $0.5 \mathrm{~m}$ from the edge of the bed which had sediment surfaces covered by plastic sheeting to determine whether recruitment onto plant mimics was from underlying sediments or from outside plots. Density of total copepods was highest on plant mimics with vegetation immediately adjacent to clipped areas inside the natural seagrass bed after $5 \mathrm{~d}$. Densities of total copepods on mimics placed outside the bed were $5 \times$ higher than those inside the bed and the covering of sediment significantly reduced recruitment. The dominant copepod species, Bulbamphiascus sp., recruited to mimics irrespective of sediment border and probably invaded mimics from underlying sediments, although this was not true for other common species. While plant arrangement may influence recruitment of some copepod species, altering access to a source pool had a much greater effect on copepod densities on plant mimics.
\end{abstract}

\section{INTRODUCTION}

Evaluation of immigration/recruitment of new individuals into and emigration of previously resident members from a population has redirected thoughts about spatial scales over which population level phenomenon should be addressed (Wiens 1989). This perspective is especially true for studies of marine benthic organisms (e.g. Underwood \& Fairweather 1989) including organisms in the meiofaunal size range (e.g. Walters 1988). In contrast to many larger macrofaunal organisms that are relatively sedentary as adults but have a dispersing larval stage, movement of both young and adult stages of meiofaunal copepods has been recorded (Bell et al. 1988). Thus consequences of migration for meiofaunal copepods may not be limited to a discrete age interval but present a continual challenge over their life span.

The concept of movement or recruitment of individuals over various spatial scales becomes especially intriguing in a benthic system such as seagrass beds where above-ground vegetative structures cover extensive areas of otherwise bare sediments. Moreover, the arrangement (defined here as the spacing and density of plants within a designated area of substratum) of above-ground seagrass structure is notably often patchy. Within a larger seagrass bed, areas ranging from less than $1.0 \mathrm{~m}$ to tens of meters across may sometimes be devoid of blades due to disturbance events [e.g. boat damage (Walker et al. 1989), feeding by rays, die back, etc.] and/or differential rhizomatous growth. Likewise, expansion of the bed margin may be uneven, producing a mosaic of patches of bare sediment juxtaposed with clusters of plants. Thus, organisms inhabiting the edges and more central areas of seagrass beds naturally encounter a landscape of varying arrangements of vegetative structure.

The irregular spacing of vegetation among sediments produces large-scale patches of plant structure relative to the body size of meiofaunal copepods. While above-ground seagrass structure has previously been studied as to the influence of density or heterogeneity of vegetation on other fauna (e.g. macrofauna, Stoner \& Lewis 1985, Eckman 1987; fish, Bell et al. 1987) no 
study has examined the role of seagrass plant arrangement on the smaller, extremely abundant meiofaunal crustaceans which associate with blades and live among the trapped sediments, detritus and epiphytes of the subcanopy. It is unclear how structures protruding above the surface impact migration or movement of not only those animals which directly utilize epibenthic structures, but also underlying sediment-dwelling populations (see Palmer 1986).

A number of analogous studies in terrestrial systems have addressed the effect of plant arrangement on insect colonization and/or behavior (see Kareiva 1982, Plowright \& Galen 1985, Denno \& Roderick 1990). In contrast to meiofaunal copepods which use plant structure indirectly, these studies focus on host specificity. For meiofaunal organisms where the spacing of vegetation among sediments is relatively large compared to their own body size, sediment/vegetation mosaics may directly or indirectly impact populations through a variety of mechanisms including alteration of predator (e.g. shrimp, small fish) activity, modification of water flow which may passively entrain copepods or influence epiphytic growth, and/or changes in copepod behavior. Accordingly, recruitment of meiofauna onto plant structures may be affected when features of the vegetative landscape are modified.

Our study reported here utilizes a manipulative approach to investigate movement of seagrass associated copepods relative to the spatial arrangement of plant mosaics. We investigate recruitment (defined here as invasion of plants and short-term post-invasion events) of copepods onto plant structure within plots with either different size sediment borders inside a bed, and/or a partial border at the margin of a bed. In order to help interpret our findings we also investigate how elimination of a neighborhood source of recruits impacts movement onto plants.

\section{METHODS AND MATERIALS}

The study consisted of multiple sets of experiments conducted in a seagrass bed in Pauatahanui Iniet, near Wellington, New Zealand. The intertidal sediment bank is dominated by the eelgrass Zostera capricorni with blade densities approaching a maximum of about 400 blades $\mathrm{m}^{-2}$. The fauna typically found in seagrass beds at this site includes both true phytal (blade-dwelling) (e.g. Tisbe, Porcellidium spp.) and itinerant forms (e.g. Halectinosoma, Ectinosoma spp.) which inhabit both sediments and blade surfaces (Hicks 1986). A subcanopy of primarily sediment-dwelling taxa (Bulbamphiascus, Paralaophonte, Halicyclops spp.) also occurs at this site. All of these species are capable of swimming to a greater or lesser extent. Furthermore, the beds at this site are of nonuniform morphology: patches of plants are separated by open sediment and bed margins may be convoluted. The Pauatahanui seagrass bed with its variation in arrangement of landscape features, along with background information on copepod species distribution (Hicks 1986, Bell et al. 1988), thus serves as a useful model to examine movement of various meiofaunal copepods, by either active or passive means, onto plant structure.

All experiments used artificial seagrass plants to examine meiofaunal recruitment onto blade structure. Each artificial seagrass unit consisted of 6 lengths of $150 \mathrm{~mm}$ and 2 lengths of $50 \mathrm{~mm}$ polypropylene ribbon attached basally to a nail anchor (see Hicks 1989 for further details). Individual plant units had a surface area equivalent to $100 \mathrm{~cm}^{2}$. The use of plant mimics eliminated any confounding effects of differences in blade density, size, age or degree of epiphytism of experimental vegetation.

Experiment 1. A pilot field experiment was conducted in June-July 1987 to determine the time course for colonization of mimics and to establish at what point sampling should occur to ensure recovery of an adequate number of specimens for further analysis. One hundred and forty mimics were planted into a haphazardly chosen area of $0.50 \times 0.50 \mathrm{~m}$ at a distance of $0.5 \mathrm{~m}$ from the margin of a bed. On Days $0.5,1,2,4,6,8,12$, 16 , and 31, five plant units were removed from this plot and returned to the laboratory for processing.

Experiment 2. Using the information from Expt 1 (see 'Results'), a second series of field experiments was designed to assess the effect of plant arrangement on recruitment of subcanopy and itinerant species to mimics. These groups of species were of major focus in the study because they were the most abundant recruits to mimics on Day 4 of Expt 1, a length of time we regarded as optimal not only for colonization of mimics (see Table 1) but also for consideration of logistical constraints. Samples in Expts 2 to 4 circumscribed this time period (e.g. Day 3 and 5). The experiments were conducted in haphazardly-located interior sections of a large, natural Zostera bed during July 1989 During daytime low tide, artificial plant units were emplaced into 2 plots measuring $0.25 \times 0.5 \mathrm{~m}$ in which live above-ground plants had been previously clipped to the sediment surface and removed. Units were planted at a density of 100 units per plot. In Expt 2, 3 different sets of interspersed plots were constructed resembling variation in bed morphology: one with natural vegetation immediately surrounding the experimental units ( $=0$ border), one with natural vegetation clipped up to $0.5 \mathrm{~m}$ from the experimental plot edges ( $=0.5$ border) and one with natural vegetation clipped up to $1.0 \mathrm{~m}$ from plot edges ( $=1.0$ border). Zero and 0.5 border plots were sampled 3 and $5 \mathrm{~d}$ after plot 
construction; 1.0 border plots were sampled on Day 3 only. On all sampling dates, 10 experimental units were removed from each plot, and returned to the laboratory for immediate processing.

Experiment 3 . This was designed to examine recruitment of fauna onto plant mimics outside the natural bed margin. Two experimental plots of the same dimensions as in Expt 2 were established simultaneously with the experimental plots inside beds. These plots were located $0.5 \mathrm{~m}$ from the edge of the bed and were ca $3 \mathrm{~m}$ from each other. No clipping was conducted in this area as vegetation was not present. Ten plant units were collected from each plot 3 and $5 \mathrm{~d}$ after planting and processed further in the laboratory.

Experiment 4. A set of experimental plots was established to determine whether recruitment onto plants was from underlying sediments or from areas outside the plots. Two types of plots were constructed outside the seagrass bed, $0.5 \mathrm{~m}$ from the bed edge. One set consisted of 100 plant units in each of two $0.5 \times 0.25 \mathrm{~m}$ plots, an identical arrangement to Expts 2 and 3, while an additional set differed in that all experimental units were planted into sediment which was covered by plastic sheeting $(0.30 \mathrm{~m} \times 0.55 \mathrm{~m})$. Plastic treatments alternated with open sediment areas. Ten units were collected from each array $3 \mathrm{~d}$ after units were emplaced into plots and transported to the laboratory for processing. As an additional check on ambient densities of copepods in natural subcanopy and outside bed sediments, 6 cores (area $=4.15 \mathrm{~cm}^{2}$ ) were taken from each area and sorted for most abundant copepod species.

In the laboratory all experimental units were shaken vigorously in $70 \%$ alcohol; this process was effective in removing $95 \%$ of blade-associated fauna. Organisms were then rinsed onto a $63 \mu \mathrm{m}$ sieve along with any sediment that had accumulated on blades or around the basal sections and transferred to small petri dishes. Fauna were enumerated and identified to species, sex and life history stage. As a measure of amount of sediment deposited on blade mimics, sediment in petri dishes was categorized as low, moderate, high or very high depending on the relative amount of sediment cover of gridded dish bottoms (see below).

Plant mimics were randomly emplaced $0.5 \mathrm{~m}$ from the bed margin and retrieved after $3 \mathrm{~d}$ to quantify sediment accumulation on experimental units. Twentyfive plant units were returned to the laboratory and sediment washed onto $63 \mu \mathrm{m}$ sieves using the procedure described above for faunal extraction. Sediments were classified as low, moderate, high or very high as above but were also subsequently collected from dishes for dry weight determination. This procedure provided a quantification of the above-sediment categories.

Statistical analyses. All data were recorded as number of individuals per plant, being equivalent to $100 \mathrm{~cm}^{2}$ of blade surface. Because treatments are constrained in their randomization in Expts 2 to 4, each mimic or experimental unit was considered a subsample (see also Hicks 1989). Results for the colonization time course (Expt 1) were subjected to a series of sequential t-tests (e.g. Day 0.5 vs 1 ; Day 1 vs 2 ) to determine if significant differences existed between each pair of dates. When appropriate, plots were treated as blocks to evaluate whether any spatial effects of position of plots within or outside of beds existed. ANOVA with plots as blocks was used to evaluate differences in copepod abundance on mimics from various experimental treatments (i. e. border, cover, time after planting). A Bartletts test for homogeneity of variance was employed prior to ANOVA and transformation applied if necessary. Category of sediment accumulation ( $1=$ low, $2=$ moderate, $3=$ high, $4=$ very high) was tested vs copepod abundance using a Spearman rank correlation test. All tests were evaluated at the $p=0.05$ level of significance.

\section{RESULTS}

\section{Experiment 1}

Mimic plants were quickly colonized by meiofaunal copepods in Expt 1 (Table 1). After $1 \mathrm{~d}$, copepod density levels changed littie over the $31 \mathrm{~d}$ interval of the June 1987 experiment. While copepod abundance was significantly lower on Day 0.5 compared to Day 1 (t-test, $\mathrm{p}<0.01$ ) no significant difference was detected among copepod densities for any other paired comparison of dates. The numerically co-dominant species were Paralaophonte sp. and Bulbamphiascus sp. (Table 1), both forms found predominantly in subcanopy sediments and occassionally on natural blades (Hicks 1986). Phytal species showed a general increase over the latter half of the $31 \mathrm{~d}$ period. Thus, within a short time (2 to $4 \mathrm{~d}$ ), the total number of copepods on plant mimics attained density levels similar to that of natural blades in June 1988 (mean density $=30.9$ per plant unit; Hicks unpubl. obs.) and remained so for greater than $3 \mathrm{wk}$. Given the extended period of time for phytal species to stabilize abundance, it is suggested that some conditioning of the blades may be necessary for persistent recruitment. We thus eliminate phytal species from experimental evaluation.

\section{Experiment 2}

In Expt 2 (July 1989) examining border effects, the highest density of sediment dwelling and itinerant 
Table 1 Colonization of mimic plants $0.5 \mathrm{~m}$ from grassbed margin by total copepods, the 2 dominant sediment-dwelling species and those categorized by Hicks (1986) as phytal and itinerant species during the $31 \mathrm{~d}$ experiment (June-July 1987). Numbers represent mean densities and standard deviation, $\mathrm{n}=5 \mathrm{mimic}$ units per date. \% Bulb.: percent composition of Bulbamphiascus sp.; \% Para. : percent composition of Paralaophonte sp.

\begin{tabular}{|crrrrrr}
\hline Day & No. of copepods (SD) & \% Bulb. & \% Para. & \% Itinerant & \% Phytal \\
\hline 0.5 & 4.8 & $(2.3)$ & 16.7 & 25.0 & 16.7 & 29.2 \\
1 & 25.0 & $(16.8)$ & 23.2 & 27.2 & 16.0 & 5.6 \\
2 & 33.0 & $(22.2)$ & 27.9 & 26.7 & 3.7 & 0.9 \\
4 & 36.8 & $(19.2)$ & 38.0 & 32.6 & 3.7 & 1.6 \\
6 & 20.6 & $(12.8)$ & 21.0 & 33.1 & 18.5 & 12.9 \\
8 & 24.8 & $(8.6)$ & 28.7 & 26.3 & 16.8 \\
12 & 33.4 & $(22.6)$ & 12.4 & 29.0 & 29.6 & 29.6 \\
16 & 37.2 & $(13.8)$ & 7.1 & & 10.6 & 40.7 \\
\hline
\end{tabular}

copepods was recorded on plant mimics with natural vegetation located immediately adjacent $(0 \mathrm{~m}$ border $)$ after 3 and 5 d (Figs. 1 \& 2). Total copepod density did not significantly differ between blocks ( $\mathrm{p}=0.365, F=$ $1.3, \mathrm{df}=1)$ nor among treatments $(\mathrm{p}=0.23, F=1.7 \mathrm{df}$ $=2$ ) after $3 \mathrm{~d}$ (Fig. 1). A 2-way ANOVA for total copepods examining density by day ( 3 or 5 ) and treatment $(0 \mathrm{~m}$ border, $0.5 \mathrm{~m}$ border) with plots as blocks, indicated no block effect $(p=0.10, F=2.87, \mathrm{df}=1)$ and no day effect ( $p=0.47, F=0.516$, df $=1)$, but a significantly lower number of copepods in the $0.5 \mathrm{~m}$ treatment ( $\mathrm{p}=0.035, F=4.64$, df $=1$ ) was recorded compared to treatments with no sediment borders $(0 \mathrm{~m}$ border) (Figs. $1 \& 2$ ). Juvenile and adult stages of all copepod species dominated samples and few nauplii were collected.

In Expts $2 \& 3,5$ species of meiofaunal copepods were regularly found on plant mimics in all border treatments inside beds (Table 2). Bulbamphiascus sp., a subcanopy sediment dweller and swimmer, was overall

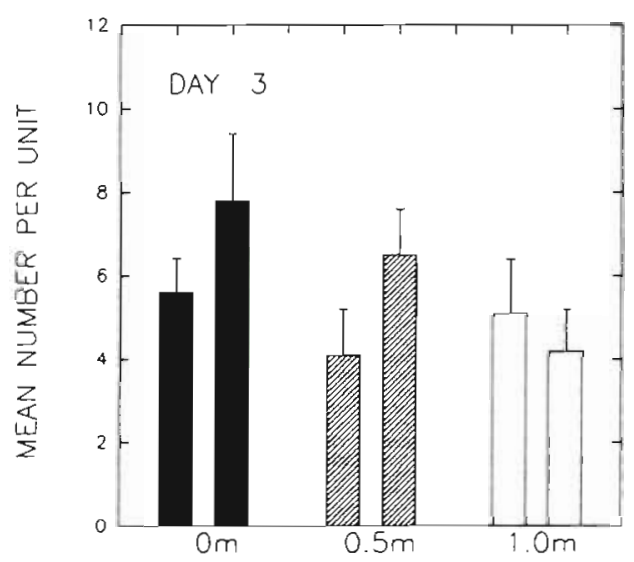

Fig. 1. Mean copepod abundance on plant mimics from various border treatments $(0,0.5,1.0 \mathrm{~m})$ inside seagrass bed after $3 \mathrm{~d}$. Each treatment is represented by 2 plots (blocks). Standard errors of subsamples are presented to provide information on within-plot variability

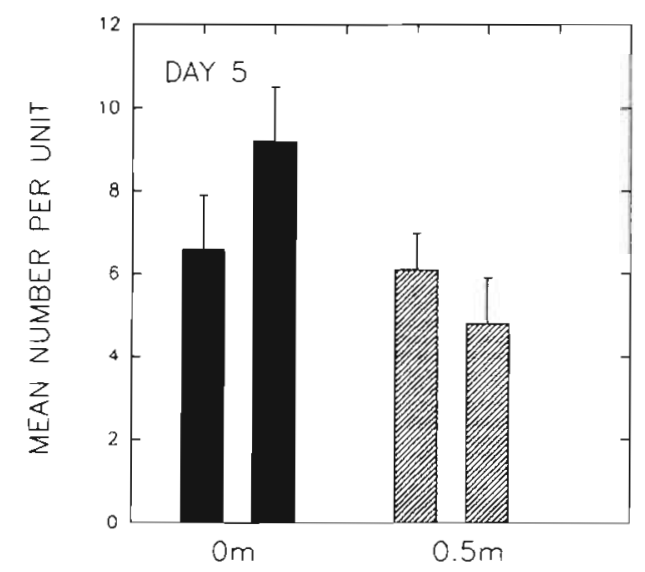

Fig. 2. Mean ( $+S E$ ) copepod abundance on plant mimics from 0 and $0.5 \mathrm{~m}$ border treatments after $5 \mathrm{~d}$. Each treatment is represented by 2 plots (blocks)

the most abundant species in every treatment, but Paralaophonte sp. and Halicyclops sp. were also common on mimics in the 0 and 0.5 border treatments (Table 2). Bulbamphiascus and Paralaophonte sp. were numerically dominant and itinerant species frequently encountered on natural blades collected in July 1989

Table 2. Densities of abundant copepod species on plant mimics from various border treatments $(0,0.5,1.0 \mathrm{~m})$ on Day 3 . Each value represents the mean of subsamples from each plot ( $A$ or $B$ ) inside seagrass beds

\begin{tabular}{|lcccccccc|}
\hline Species & \multicolumn{7}{c|}{$\begin{array}{c}\text { Border } \\
\end{array}$} & \multicolumn{7}{c}{$\begin{array}{c}0.5 \\
\end{array}$} & A & B & A & B & A & B \\
\hline Bulbamphiascus sp. & 1.5 & 1.9 & 1.4 & 1.2 & 1.5 & 1.2 \\
Halicyclops sp. & 1.7 & 1.3 & 1.4 & 1.3 & 0 & 0.8 \\
Enhydrosoma variable & 0.4 & 0.3 & 0.3 & 0.2 & 0.2 & 1.4 \\
Halectinosoma hydrofuge & 0.2 & 0.3 & 0.4 & 0.1 & 0.7 & 0.3 \\
Paralaophonte sp. & 2.0 & 1.5 & 1.0 & 0.6 & 0.2 & 0.3 \\
\hline
\end{tabular}


(Hicks \& Bell pers. obs.). While mean densities of the numerically dominant species, Bulbamphiascus sp., and less common taxa, Enhydrosoma variable and Halectinosoma hydrofuge, overlapped in magnitude among all border treatments, a decline in abundance of Halicyclops sp, and Paralaophonte sp, as border size increased was apparent (Table 2). The slope of the regression line $(-0.92)$ of density of these 2 species $(Y)$ versus border distance $(X)$ is significantly different from zero ( $\mathrm{p}<0.01$ ). Curiously, phytal species (particularly Tisbe, and Porcellidium) were uncommon both on mimics and natural blades (Bell \& Hicks pers, obs.) during these experiments in 1989 although in previous years they dominated the blade fauna in the month of July (Hicks 1986, Hicks unpubl.).

\section{Experiment 3}

Expt 3, conducted at a distance of $0.5 \mathrm{~m}$ from the bed edge, demonstrated similar rapid colonization of mimics (Fig. 3) as recorded in Expt 2, conducted inside the bed. Densities of copepods on mimics outside the bed were, however, 5 times higher than those on

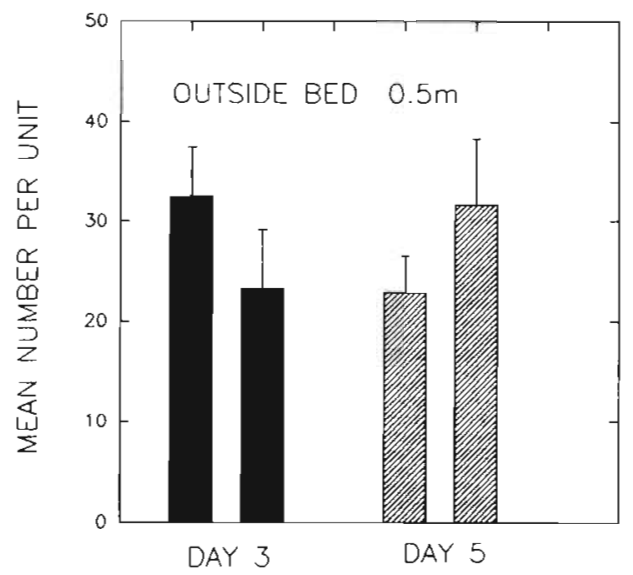

Fig. 3. Mean (+SE) copepod abundance on plant mimics from $0.5 \mathrm{~m}$ border treatment from outside the seagrass bed after $3 \mathrm{~d}$. Each treatment is represented by 2 plots (blocks)

mimics emplaced inside the bed (cf. Fig. 2 vs 3). Results were consistent over time and spatial scale; a 1-way ANOVA on days ( 3 vs 5) using plot as blocks indicated no day ( $\mathrm{p}=0.90, F=0.015$, df $=1$ ) or block effects ( $\mathrm{p}=$ $0.11, F=2.7$, df $=1$ ), similar to findings from mimics planted in interior bed areas.

\section{Experiment 4}

Results from Expt 4 demonstrated that covering of sediments had a major impact on recruitment of

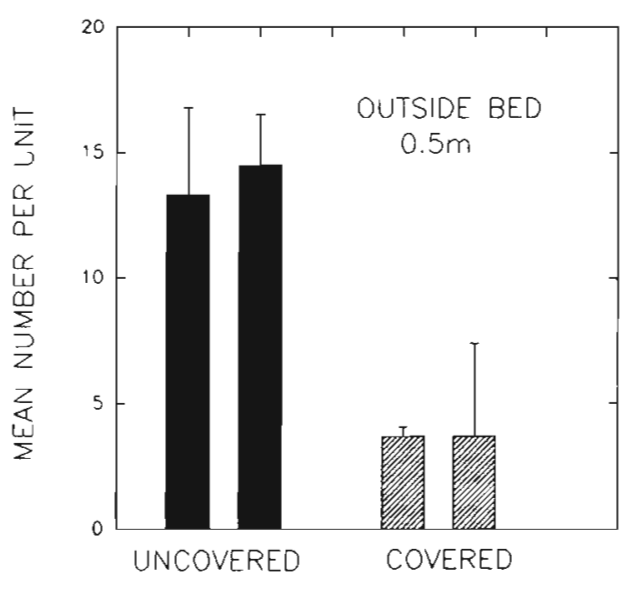

Fig. 4. Mean (+SE) copepod abundance on plant mimics from $0.5 \mathrm{~m}$ border treatment outside the seagrass bed after $3 \mathrm{~d}$. Uncovered: mimics planted directly into sediment; covered: mimics planted into plastic sheet over sediments. Each treatment is represented by 2 plots (blocks)

copepods to plant mimics over 3 d (Fig. 4). Significantly more copepods were recovered from blade mimics planted into uncovered versus covered sediments ( $p<$ $0.0001, F=29.4$, df $=1$ ) and no block effect was detected $(\mathrm{p}=0.89, F=0.0018, \mathrm{df}=1$ ).

Tabulation of mean densities in each of 2 plots for the 4 most frequently encountered species indicated that in 7 of 8 cases higher densities were recorded in uncovered vs covered plots (Table 3 ) and the probability of this occurring by chance alone is less than 0.05. In some cases no recruitment was observed in the plasticcovered plots and Bulbamphiascus abundance on uncovered mimics was ca 6 times higher than on mimics planted into plastic (Table 3).

Table 3. Mean densities of most abundant copepod species in sediments inside and outside beds ( $n=6$ cores) and in mimic treatments at seagrass margin on Day 3. Uncovered: mimics planted into natural undisturbed sediments; covered: mimics planted into plastic covered sediment. A and B refer to plots

\begin{tabular}{|c|c|c|c|c|}
\hline \multirow[t]{2}{*}{ Copepod species } & \multicolumn{4}{|c|}{ Sediments } \\
\hline & \multicolumn{2}{|c|}{ Inside } & \multicolumn{2}{|c|}{ Outside } \\
\hline Bulbamphiascus sp. & \multicolumn{2}{|c|}{18.0} & \multicolumn{2}{|c|}{49.0} \\
\hline Halicyclops sp. & \multicolumn{2}{|c|}{1.0} & \multicolumn{2}{|c|}{1.0} \\
\hline Paralaophonte sp. & \multicolumn{2}{|c|}{6.0} & \multicolumn{2}{|c|}{6.0} \\
\hline \multirow[t]{4}{*}{ Halectinosoma hydrofuge } & \multicolumn{2}{|c|}{7.0} & \multicolumn{2}{|c|}{22.0} \\
\hline & \multicolumn{4}{|c|}{ Mimics } \\
\hline & \multicolumn{2}{|c|}{ Uncovered } & \multicolumn{2}{|c|}{ Covered } \\
\hline & $A$ & $\mathrm{~B}$ & $A$ & $\mathrm{~B}$ \\
\hline Bulbamphiascus sp. & 6.4 & 6.7 & 1.3 & 0.8 \\
\hline Halicyclops sp. & 1.9 & 1.8 & 1.3 & 0.8 \\
\hline Paralaophonte sp. & 0.5 & 1.7 & 0.6 & 0.2 \\
\hline Halectinosoma hydrofuge & 3.1 & 1.8 & 0 & 0 \\
\hline
\end{tabular}




\section{Sediment deposition on mimics}

The amount of sediment deposited on blade mimics was highly variable and ranged from low to very high for treatments both inside and outside the natural seagrass bed (Table 4). Mean dry weight of sediment was similar (ca 0.3 to $0.6 \mathrm{~g}$ per plant mimic) across experimental treatments (Table 4). A Spearman correlation test of

Table 4. Mean level of sediment accumulation on plant mimics from various treatments after $3 d(n=20$ for each treatment). Categorization of sediments based upon visual coverage of processing dish $\left(15 \mathrm{~cm}^{2}\right)$ and dry weight of sediments from 25 plant mimics

\begin{tabular}{|lc|}
\hline Category no. and type & Dry weight \\
\hline 1. Little sediment & $<0.300 \mathrm{~g}$ \\
2. Moderate sediment & $0.300-0.600 \mathrm{~g}$ \\
3. Heavy sediment & $0.601-0.900 \mathrm{~g}$ \\
4. Very heavy sediment & $>0.900 \mathrm{~g}$ \\
& \\
Mean sediment load category & Category \\
Treatment & 2.2 \\
& \\
No border, inside bed & 1.9 \\
$0.5 \mathrm{~m}$ border, inside bed & 2.1 \\
$1.0 \mathrm{~m}$ border, inside bed & 1.9 \\
\hline $.5 \mathrm{~m}$ border, outside bed & \\
\hline
\end{tabular}

sediment category (1 to 4 ) versus copepod density on mimics collected from outside and inside the bed after $3 \mathrm{~d}$ indicated a significant correlation $(n=78, r=0.277$, $p<0.05$ ). Sediment accumulation on blades was highly variable in spite of the constant blade morphology, age and plant density used in experimental plots.

\section{DISCUSSION}

The overall findings confirm that differences in copepod recruitment rates exist over the scale of landscape features in a New Zealand seagrass bed. Recruitment by preadult and adult stages of copepods onto plant mimics occurred rapidly but varied among the different arrangements of borders of seagrass vegetation. Results from the initial colonization experiment suggest that recolonization levels detected after 3 to $5 \mathrm{~d}$ may be sustained over a number of weeks.

Apart from establishing the scale over which recruitment may vary within seagrass beds, important faunal differences were also identified. Given a shorter distance for organisms to move from an assumed source of recruits, previous investigators have predicted and reported an increased rate of initial colonization (Gunnill 1982, Virnstein \& Curran 1986). The present experi- ments have shown this to be so for only some of the common species (Halicyclops sp., Paralaophonte sp.) while others (Bulbamphiascus sp., Halectinosoma hydrofuge, Enhydrosoma variable) colonized plant mimics at consistent rates irrespective of distance barriers from a putative subcanopy recruitment source (Table 2).

The differential rates of colonization may well relate to the swimming competency of each species. Bulbamphiascus sp. and Halectinosoma hydrofuge colonize plants both inside and outside beds at similar rates, relative, of course, to the size of the neighborhood source pool (Table 3). Halicyclops sp. and Paralaophonte sp., however, have some difficultly colonizing plants across the $1 \mathrm{~m}$ sediment border inside beds. Bulbamphiascus and $H$. hydrofuge have been shown to be amongst the most capable swimming species in seagrass beds at this site, together accounting for about $40 \%$ of all individuals collected in emergence traps (see Table 8 in Hicks 1986). On the other hand, Halicyclops and Paralaophonte demonstrate lower levels of capture in traps (together about $5 \%$ of total) which would suggest a reduced swimming capability, thereby providing an explanation for the pattern in Table 2. These results reiterate that the scale over which recruitment varies as plant arrangement is altered appears to be species dependent.

The results from experiments performed outside the bed provide direct evidence that immediate adjacency of dense seagrass vegetation is not a prerequisite for the recruitment of high densities of copepods, a pattern also previously detected for insects on host plants (Kareiva 1987). Earlier work in Pauatahanui Inlet had shown that abundances of Bulbamphiascus sp. were highest on sediments beneath a dense seagrass canopy, with much lower density outside of the bed in open sediments (Hicks 1986). In the present experiments this trend was reversed with higher abundances outside at bed margins (see Table 3). Examination of copepod species abundances in sediment cores and on uncovered plant mimics outside the bed suggests that the high densities of Bulbamphiascus on plant mimics may simply reflect the higher ambient pool of potential colonists of this species in outside underlying sedjments (see Table 3). Certainly the experiments with covered sediments confirm this suggestion as low numbers were found on mimics when a barrier to upward movement out of the sediment and onto mimics was in place (Fig. 4, Table 3). While plant arrangement may influence recruitment levels (a density difference of ca $25 \%$ between border treatments), altering access to one source pool had a much greater influence on resultant densities on plant mimics (a $70 \%$ change in densities when source pool was altered). These combined results provide an important warning the effects 
of plant arrangement may only be deciphered if equivalent source pools are being compared. Hence, comparison of results of experiments inside vs outside edges of beds must proceed cautiously.

Variation in landscape features and events that cause such variation over the spatial scale of a seagrass bed may operate to produce localized differences in copepod density levels. Small-scale changes in physical characteristics such as detrital accumulation (Meyer \& Bell 1989), flow (Eckman 1987) or light and epiphyte load (Hall 1988, Hall \& Bell 1988) have been reported to directly or indirectly alter faunal abundance. The positive association of copepod density and sediment load on plants across all treatments suggests that further examination of this relationship may be warranted. It is also consistent with previous investigations linking meiofaunal abundance to the level of deposited sediment on rocky shore algae (Hicks 1985 for review, Gibbons 1988). Moreover, changing seagrass landscapes may affect reproductive behavior of copepods via modification of migration linked to reproductive activities (Bell et al. 1988). The relative effect of alteration of landscape features will thus depend on the way these associated physical or biological factors impact directly on the immigration process. Arguably, alteration of immigration by border arrangement should be added to the list of features by which spatial distribution of vegetation may affect populations of associated fauna.

Data exist which lend support to the concept that copepod populations are maintained by immigration of members from outside source pools. Other studies on copepods from seagrass beds in Florida have demonstrated (1) movement of copepods into the water column (Walters \& Bell 1986; Bell et al. 1989), and (2) changes in population densities that could not be explained by in situ reproduction of organisms inhabiting beds of $>100^{2}$ area (e. g. Meyer 1990, Hall \& Bell unpubl). These studies together with information on seagrass inhabitants from New Zealand which exhibit similar movement capabilities (Hicks 1986, Bell et al. 1988, this study) suggest that the spatial scale over which some copepod populations should be examined within vegetated sites may extend beyond the borders of a single bed, with immigration of both young and adult stages from outside source pools a common event.

It is clear that understanding the impact of landscape patterns on fauna in seagrass beds will involve concurrent recording of vegetation patch dynamics and faunal responses. As habitat structure of macrophytes is altered, so too may be the set of complex interactions among associated fauna and flora (Heck \& Crowder 1990). While the results presented here focus primarily on copepods and seagrass blades, potential implications exist for other marine systems where habitat structure is of non-uniform distribution.
Acknowledgements. The Staff of the Natural History Unit of the National Museum of New Zealand generously aided in the construction of the 600 plant units used in this study. K. Walters made comments on a previous draft of the manuscript. Anonymous reviewers clearly spent much time assisting us in rethinking some of our ideas. To all we are grateful. Supported in part by Florida Sea Grant (Award \# R/C-E-28 to S.S. Bell.)

\section{LITERATURE CITED}

Bell, S. S., Hicks, G. R. F., Walters, K. (1988). Active swimming in meiobenthic copepods of seagrass beds: geographic comparisons of abundances and reproductive characteristics. Mar. Biol. 98: 351-358

Bell, S. S., Hicks, G. R. F., Walters (1989). Experimental investigations of benthic reentry by migrating meiobenthic copepods. J. exp. mar. Biol. Ecol. 130: 291-303

Bell, J. D., Westoby, M., Steffe, A. F. (1987). Fish larvae settling in seagrass: Do they discriminate between beds of different leaf density? J. exp. mar. Biol. Ecol. 111: 133-144

Denno, R. F., Roderick, G. K. (1990). Influence of patch size, vegetation texture, and host plant architecture on the diversity, abundance, and life history styles of sap-feeding herbivores. In: Bell, S. S., McCoy, E. D., Mushinsky, H. R. (eds.), Habitat structure: the physical arrangement of objects in space. Chapman and Hall, London, 169-196.

Eckman, J. E. (1987). The role of hydrodynamics in recruitment, growth and survival of Argopecten irradians (L.) and Anomia simplex (D'Orbigny) within eelgrass meadows. J. exp. mar. Biol. Ecol. 106: 165-191

Gibbons, M. J. (1988). The impact of sediment accumulation, relative habitat complexity and elevation on rocky shore meiofauna. J. exp. mar Biol. Ecol. 122: 225-241

Gunnill, F. C. (1982). Macroalgae as habitat patch islands for Scutellidium lamellipes (Copepoda: Harpacticoida) and Ampithoe tea (Amphipoda: Gammaridae). Mar. Biol. 69: $103-116$

Hall, M. O. (1988). Dynamics and interactions of epiphytic macroalgae and meiofauna on the seagrass. Thalassia testudinum. Ph. D. dissertation, University of South Florida, Tampa

Hall, M. O., Bell, S. S. (1988). Responses of small motile epifauna to complexity of epiphytic algae on seagrass blades. J. mar. Res 46: 613-630

Heck, K. L. Jr., Crowder, L. B. (1990). Habitat structure and predator-prey interactions in vegetated aquatic ecosystems. In: Bell, S. S., McCoy, E. D., Mushinsky, H. R. (eds.) Habitat structure: the physical arrangement of objects in space. Chapman and Hall, London, p. 281-299

Hicks, G. R. F. (1985). Meiofauna associated with rocky shore algae. In: Moore, P. G., Seed, R. (eds.) The ecology of rocky coasts. Hodder and Stoughton, London, p. 34-60

Hicks, G. R. F. (1986). Distribution and behavior of meiofaunal copepods inside and outside seagrass beds. Mar. Ecol. Prog. Ser. 31: 159-170

Hicks, G. R. F. (1989). Does epibenthic structure negatively affect meiofauna? J. exp. mar. Biol. Ecol. 133: 39-55

Kareiva, P, (1982). Experimental and mathematical analyses of herbivore movement: quantifying the influence of plant spacing and quality of foraging discrimination. Ecol. Monogr. 52: 261-282

Kareiva, P. (1987). Habitat fragmentation and the stability of predator-prey interactions. Nature, Lond. 326: 388--390

Meyer, H. A. (1990). Ecology of the harpacticoid Metis holothuiriae: patterns of population structure, detrital rela- 
tionships and synchronization of recruitment. Ph. D. dissertation, University of South Florida, Tampa

Meyer, H. A., Bell, S. S. (1989). Response of harpacticoid copepods to detrital accumulation on seagrass blades: a field experiment with Metis holothuriae (Edwards). J. exp. mar. Biol. Ecol. 132: 141-149

Palmer, M. A. (1986). Hydrodynamics and structure: interactive effects on meiofaunal dispersal. J. exp. mar. Biol. Ecol. 104: $53-68$

Plowright, R. C., Galen, C. (1985). Landmarks or obstacles: the effects of spatial heterogeneity on bumblebee foraging and behavior. Oikos 44: 459-464

Stoner, A., Lewis, G. R. (1985). The influence of quantitative and qualitative aspects of habitat complexity in tropical seagrass meadows. J. exp. mar. Biol. Ecol. 94: 19-40

Underwood, A. J., Fairweather, P. G. (1989). Supply side

This article was presented by R. M. Warwick, Plymouth, UK ecology and benthic marine assemblages. Trends Ecol. Evol. 4: 16-20

Virnstein, R. W. Curran, M. C. (1986). Colonization of artificial seagrass vs. time and distance from source. Mar. Ecol. Prog. Ser. 29: 279-288

Walker, D. I., Lukatelich, R. J., Bastyan, G., McComb, A. J. (1989). Effect of boat moorings on seagrass beds near Perth, western Australia. Aquat. Bot. 36: 69-77

Walters, K. (1988). Diel vertical migration of sediment associated meiofauna in subtropical sand and seagrass habitats. J. exp. mar. Biol. Ecol. 117: 169-186

Walters, K, Bell, S. S. (1986). Diel patterns of active vertical migration in seagrass meiofauna. Mar Ecol. Prog. Ser. 34: 95-103

Wiens, J. A. (1989) Spatial scaling in ecology. Function. Ecology 3: $385-397$

Manuscript first received: September 9, 1990

Revised version accepted: March 12, 1991 